\title{
Balancing tension in transferred slips in some dynamic procedures for claw finger correction
}

\author{
G. N. Malaviya \\ Plastic \& Reconstructive Surgery Unit, Central Jalma Institute for Leprosy, Tajganj, Agra, India
}

Address for correspondence: Dr. Govind Narain Malaviya, Post Box 25, GPO, Mall Road, Agra-282 001, India.

E-mail:govindmalaviya@rediffmail.com

\section{ABSTRACT}

The adjustment of tension on the tendon slips which are being inserted to correct finger clawing, is the critical step in claw finger correction procedures. Several methods have been described in literature but ultimately every thing boils down to the experience of the operating surgeon who has to make decisions on the operating table. Attempt is being made to translate this experience (an abstract noun) in to words to help make life easier for the surgeons who are venturing into the field of corrective surgery and do not have enough experience to back them.

\section{KEY WORDS}

Claw finger, Tendon transfer, Tension equalizer

\section{INTRODUCTION}

he most important step in all tendon transfer procedures to correct finger clawing, is suturing of the transferred tendon slip to the extensor expansion or flexor sheath of each finger at appropriate tension. Terms like mild, moderate or maximum have been widely used in describing the tension. The tension at which the slip should be sutured, however has never been stated accurately in most of the descriptions. ${ }^{1}$ It appears that tension is adjusted arbitrarily and the results of the operation therefore are more dependent on the experience of the operator than on any scientific assessment of the amount of tension actually required for each finger. This subjective assessment of tension appears to be an important factor responsible for under correction or over correction of deformities.

While describing palmaris transfer for correction of finger clawing, Antia ${ }^{2}$ has suggested low tension for index and middle fingers and moderate to high tension for ring and little fingers. Tension was tested by pulling on the motor tendon in the proximal forearm and readjusted if required, limb immobilized in lumbrical position after skin suturing. Others have described the tension in millimeters or in terms of degree of metacarpophalangeal (MCP) joint flexion on the slip to be sutured. Fritschi ${ }^{3}$ has said that "It is absolutely essential that all four slips should be at an equal tension when the hand is in neutral position with respect to the abduction and adduction at wrist."

\section{Available Techniques}

The techniques to equalize or balance tension across the four tendon slips are different for lateral band insertions and "lasso" procedures. In general, the tensions are managed with a combination of positioning of wrist, MCP joints, proximal interphalangeal (PIP) and distal interphalangeal (DIP) joints while suturing and during postoperative immobilization. 


\section{(a) For Lateral band insertion procedures (motor routed through carpal tunnel)}

1. Use of a positioning splint: The positioning splint holds the hand in position while suturing. Several such splints are available.

(a) Fritschi's splint ${ }^{3}$ - The positioning splint holds the wrist in $30^{\circ}$ flexion, MCP joints in $60^{\circ}$ flexion and fingers fully extended at PIP and DIP joints while suturing [Figure 1]. The hand is positioned on the splint and then index finger tendon slip is pulled a little to ensure its smooth passage and then sutured to lateral band of dorsal expansion with all the slack taken up (zero tension). Next, the little finger slip is grasped, slack is taken up and tendon is then pulled $6 \mathrm{~mm}$ more (noted as tension $6 \mathrm{~mm}$ ) and sutured to the lateral band. The point of equalizing the tension is roughly $5-7 \mathrm{~mm}$ and at this point, the attached index finger slip is seen to relax. It is necessary to pull the little finger tendon sufficiently to equalize the angle of approach of tendons with reference to main stem of the tendon. Experimentally it has been shown that the amount of pull on little finger, in order to equalize this angle, is $5-7 \mathrm{~mm}^{3}$. The remaining two slips, lying between index and little fingers, are then sutured under zero tension because any extra tension put on these slips will relax the already sutured index and little finger slips. Zero tension means that the weight of the artery forceps hanging from the tendon end is taking up the slack fully before suturing the slip to lateral band.

In each finger, tendon slips are ideally sutured with three interrupted stitches of $4 / 0$ black braided silk which ensures good adhesion of the slip on to the lateral bands. If a tourniquet is being used it is released and bleeding is arrested before closing the skin. The hand is taken off the splint after skin closure, dressed appropriately and put in a plaster cast or shell keeping MCP joints in $70^{\circ}$ flexion, wrist and IP joints neutral.

Fritschi ${ }^{4}$ noted that with the above splint, distal transverse metacarpal arch (DTMA) was not maintained properly while suturing the tendon slips. As a consequence of this, ring and little fingers slips were put at a lower tension (because the palm is stretched out flat instead of having a gentle curve) resulting in reversal of DTMA. He modified his earlier splint giving a gentle curve to the ulnar side at MCP joint level and recommended separate splints for left and right hands [Figure 2a].

He subsequently designed a new splint made of solid wood having same positions for the wrist and MCP joint but a definite curve at the MCP joint level. Six grooves were provided; four to accommodate fingers and two grooves on the thumb side were left vacant. This splint can be used for left and right hands both [Figure $2 \mathrm{~b}$ ].

Karat ${ }^{5}$ pulls on little finger slip to the extent that it moves, at the same time watching the index finger slip. The moment the index tendon slip is seen to relax, the little finger tendon slip is sutured to the lateral band [Figure 3]. In practice two methods may, with advantage, be used as a check on each other.

(b) Salafia's splint ${ }^{6}$ : He designed a splint where the hand is kept in supine position. There is separate strut for each finger. The fingers are held in place with rubber bands and tensions can be separately adjusted. The MCP joints are kept $90^{\circ}$ flexed, wrist $30^{\circ}$ and IP joint in neutral position while suturing [Figure 4].

2. Suturing without splints: Srinivasan and Palande ${ }^{7}$ suggested that the hand is to be held with a thick sheet, palm facing down wards, wrist neutral or in mild flexion, MCP joints in $55^{\circ}$ flexion, PIP and DIP joints in neutral position. Index finger slip is dealt with first. It is pulled for $5 \mathrm{~mm}$, released and then sutured at zero tension i.e. just taking up the slack. Then the little finger slip is taken up, pulled to take up slack and then pulled $3 \mathrm{~mm}$ further and sutured ( $3 \mathrm{~mm}$ tension). The ring finger slip is sutured at 1 $\mathrm{mm}$ tension and the middle finger slip at zero tension. While suturing, the tendon slips are placed obliquely across the extensor expansion so that first (most proximal) suture is put to the lateral band, next one to extensor expansion between lateral band and mid part of the extensor expansion, distal most to middle portion of the extensor expansion.

After the most proximal suture is placed in all fingers, the hand is held vertically with the wrist in neutral position. The resting position of MCP joints of index and middle fingers should be about $45^{\circ}$ flexion, ring finger $50^{\circ}$ and that of the little finger about $55-60^{\circ}$ flexion, very much as in a normal resting hand. PIP and DIP joints should be nearly straight. The wrist can then be extended to verify that all fingers flex equally. If any of the fingers lags behind others, re-suturing is done in that finger after further adjusting the tension. When satisfied that the tension is right, middle and distal most sutures are inserted. The limb is immobilized in a plaster cast keeping the wrist and IP joints in neutral position. MCP joint of index, middle, ring and 
little fingers are kept flexed $55^{\circ}, 55^{\circ}, 60^{\circ}$ and $70^{\circ}$ respectively.

These authors added that instead a special splint, more or less similar as described by Fritschi ${ }^{3}$, can also be used to maintain the position while suturing.

3.Measured tension technique: PV Joshi (Personal Communication) has described a method, by which the exact tension required to correct clawing of fingers is measured pre-operatively using a spring balance. A two centimeters wide leather loop is placed around the middle of proximal phalanx of the finger to be measured as shown. The loop is then attached to a spring balance. Patient is then asked to straighten the finger at PIP joint with dorsum of the hand lying flat on the table. While the patient is doing so, the spring balance is pulled slowly to keep MCP joint steady in the flexed position and tension exerted on the proximal phalanx. When PIP joint is fully extended, tension is read off the scale of the spring balance. The tension required for each finger is recorded. The patient is explained about the procedure first and one or two trial sessions are held before actual measurements are made. ${ }^{8}$

During operation, the hand is laid flat on a wire mesh and the wrist and fingers are held in position with rubber bands. The end of each slip is held by a hemostat which is in turn connected to the same spring balance with a sterile connecting rod or thick wire. The assistant pulls the balance until pre-operatively recorded tension for that particular finger is reached. At this point, the slip is sutured to extensor expansion. The finger needing least tension is dealt with first. Slips to the other fingers are sutured in an increasing order of tension [Figure 5].

4. Brand's methods ${ }^{9-12}$ : (i) Brand ${ }^{10}$ emphasized the importance of tension of the tendon suture and suggested that wrist be kept in $30^{\circ}$ flexion, MCP joint in $60^{\circ}$ flexion, PIP and DIP joints in neutral position while suturing. He said that an aluminium splint will be more convenient to use because the hand can rest on that while suturing is done. With the hand in position on a splint, the graft in each finger is first pulled and then relaxed and then stitched in position of relaxation. The graft in the little finger is stitched last and should be at a slightly higher tension as compared to others. Once all the grafts have been stitched, equality of tensions may be checked by pulling gently on the stem of the motor tendon in forearm and observing that all four fingers begin to move. After skin suturing, immobilization is done with a plaster cast keeping MCP joint $90^{\circ}$ flexed, wrist and IP joints in neutral position.

(ii) Brand ${ }^{11}$ suggested that palm of the hand can also be supported on a high block (if the splint is not available) so that wrist is $45^{\circ}$ flexed, MCP joint $80^{\circ}$ flexed and IP joints in neutral position. In this position grafts can be sutured to lateral bands with almost no tension. The graft to the little finger should be sutured last and at a slightly higher tension than other grafts. The transfer can be tested by pulling the stem of the motor in proximal forearm to see if all fingers are equally moved by the pull. The hand is immobilized in the same position as was used for suturing tendon slips [Figure 6a].

(iii) Brand ${ }^{12}$ has also suggested that a roll of gauze or towel, $4 \mathrm{cms}$. in diameter can be used if a splint is not available [Figure 6b]. When the forearm is laid prone on the table over this roll, placed under MCP joints, the wrist extends by about $45^{\circ}$ and MCP joints are flexed $90^{\circ}$. IP joints are kept neutral. However he preferred a splint made of $20 \mathrm{cms}$. wide aluminium sheet (more convenient) to which the hand can be tied while suturing. Since in this position of joints, muscles are well relaxed, no tension needs to be exerted while grafts are sutured but all slack must be taken up both in the graft proximally and in the lateral band distally. Tension can be confirmed by pulling on the stem of motor tendon. All fingers should move a little into flexion at MCP joints. If any finger is out of line with others or lags behind or pulls ahead, tendon slip to this finger can be detached and re-attached after correcting tension. The hand is immobilized in the same position as was used for suturing tendon slips.

5. Other methods: Malaviya and Srinivasan ${ }^{13}$ have suggested to use a tension equalizing splint as designed by Fritschi ${ }^{4}$ to keep wrist $30^{\circ}$ and $\mathrm{MCP}$ joints $60^{\circ}$ flexed, IP joints neutral in all fingers while suturing. They suggested that maximum tension be put on little finger slip and balance it with index finger slip. To ring and middle finger slips moderate tension, adequate enough to take up slack, was given. For immobilization they keep MCP joint $70^{\circ}$ flexed, wrist and IP joints neutral.

Anderson ${ }^{14}$ using a splint, keeps the wrist in $30^{\circ}$ volar flexion, $\mathrm{MCP}$ joints in $80-90^{\circ}$ flexion and IP joints in neutral position while suturing. He immobilizes the hand keeping MCP joint $80^{\circ}$ flexed, wrist and IP Joints neutral.

[Table 1] shows the joint positions of fingers and wrist as 
Table 1: Joints positions of fingers and wrist as used by different workers while suturing the slips to lateral bands

\begin{tabular}{|c|c|c|c|c|c|c|c|c|}
\hline \multirow[t]{2}{*}{ Used by } & \multirow[t]{2}{*}{ Time } & \multirow[t]{2}{*}{ Wrist Flexion } & \multicolumn{4}{|c|}{ MCPJ Flexion ${ }^{0}$} & \multirow[t]{2}{*}{ PIPJ \& DIPJ } & \multirow[t]{2}{*}{ Support Used } \\
\hline & & & $I$ & $M$ & $\boldsymbol{R}$ & $L$ & & \\
\hline \multirow[t]{2}{*}{ Brand $^{10}$} & $S$ & $30^{\circ}$ & $60^{\circ}$ & $60^{\circ}$ & $60^{\circ}$ & $60^{\circ}$ & Neutral & Splint \\
\hline & I & Neutral & $90^{\circ}$ & $90^{\circ}$ & $90^{\circ}$ & $90^{\circ}$ & Neutral & \\
\hline & I & $45^{\circ}$ & $90^{\circ}$ & $90^{\circ}$ & $90^{\circ}$ & $90^{\circ}$ & Neutral & Roll \\
\hline \multirow[t]{2}{*}{ Fritschi $^{3}$} & $S$ & $30^{\circ}$ & $60^{\circ}$ & $60^{\circ}$ & $60^{\circ}$ & $60^{\circ}$ & Neutral & Splint \\
\hline & I & Neutral & $70^{\circ}$ & $70^{\circ}$ & $70^{\circ}$ & $70^{\circ}$ & Neutral & \\
\hline \multirow[t]{2}{*}{ Palande ${ }^{7}$} & I & Neutral & $55^{\circ}$ & $55^{\circ}$ & $65^{\circ}$ & $70^{\circ}$ & Neutral & \\
\hline & Tension & & 0 & 0 & $1 \mathrm{~mm}$ & $3 \mathrm{~mm}$ & & \\
\hline Duerksen \& & $\mathrm{S}$ & $30^{\circ}$ & $80-90^{\circ}$ & $80-90^{\circ}$ & $80-90^{\circ}$ & $80-90^{\circ}$ & Neutral & Splint/ \\
\hline Schwarz $^{17}$ & I & $30^{\circ}$ & $90^{\circ}$ & $90^{\circ}$ & $90^{\circ}$ & $90^{\circ}$ & Neutral & Towel Roll \\
\hline Malaviya \& & S & Neutral & $60^{\circ}$ & $60^{\circ}$ & $60^{\circ}$ & $60^{\circ}$ & Neutral & Splint \\
\hline
\end{tabular}

I M R L = Index, Middle, Ring, Little fingers, $S=$ At the time of Suturing; I = At the time of immobilization

used by different workers while suturing the slips to the lateral bands.

\section{(b) For "Lasso" procedures}

(i) Zancolli ${ }^{15}$ described his technique to obtain appropriate tension for direct and indirect "lasso" procedures. For mobile fingers, held with all the joints (wrist and finger) in neutral position, only the slack in transferred slip is taken up. If the tension is correct, the proximal phalanx immediately flexes and middle and distal phalanx go into mild extension. For mild stiffness of PIP joints, MCP joints are kept in $20^{\circ}$ flexion and IP joints in neutral position while suturing. The hand is immobilized with wrist neutral, MCP joints in $20^{\circ}$ flexion and IP joints free to move, in both the situations.

(ii) Srinivasan and Palande ${ }^{7}$ recommend that on pulling the tendon slip, MCP joint of index and middle fingers should flex $30^{\circ}$ and for ring and little fingers $40^{\circ}$ and $50^{\circ}$ respectively. Once all the tendon slips have been sutured, the hand is raised to confirm tensions by observing the position of MCP joints which should flex equally on extending the wrist. The limb is immobilized in a plaster cast keeping all MCP joints flexed at $70^{\circ}$, wrist and PIP joints neutral and DIP joints free to move.

(iii) Malaviya et a ${ }^{16}$ while performing indirect and modified "lasso" suggested to keep MCP joints in $60-65^{\circ}$ flexion (more for little finger) and take up all the slack in tendon slips. The limb was immobilized with MCP joints $70^{\circ}$ flexed, wrist neutral and IP joints free to move.

(iv) Anderson ${ }^{14}$ prefers to keep the wrist neutral, MCP joints in $45^{\circ}$ flexion and IP joints in neutral position while suturing and immobilizes the hand in same position after operation. He recommends "more" tension for little finger.

Table 2 shows the joint positions of fingers and wrist as used by different workers while suturing the slips to the digital flexor sheath.

\section{DISCUSSION}

Various dynamic procedures to correct fingers clawing have been described. The critical step in all these procedure is suturing of transferred tendon slips to the new insertion site at appropriate tension proportionate to the degree of clawing as assessed pre-operatively. All fingers are not equally clawed and probably require different tensions for their correction. The pre-operative degree of clawing, dependent upon the duration of clawing and element of long flexor contracture, determine the tension to be applied. Fritschi ${ }^{3}$ advised that all contractures should ideally be corrected pre-operatively.

The complicating conditions like contractures, dorsal expansion damage, guttering of extensor tendons at MCP joint should all be corrected preoperatively because all these can result in faulty tension adjustments. The time spent in preparation does not go waste. The reward comes back in the form of straight fingers in open hand position and fingers flexing in unison to give a firm grasp. Fritschi ${ }^{4}$ recommends to use a splint which has appropriate curvature for DTMA. Preferably, separate splints are used for right and left hands so as to accommodate DTMA which 
Malaviya GN

Table 2: Joints positions of fingers and wrist as used by different workers while suturing the slips to the digital flexor sheaths

\begin{tabular}{|c|c|c|c|c|c|c|}
\hline Used by & Time & Wrist Flexion & \multicolumn{3}{|c|}{ MCPJ Flexion } & PIPJ and DIPJ \\
\hline Anderson ${ }^{14}$ & Immobilization & $10^{\circ}$ & \multicolumn{3}{|l|}{ >on little finger } & free to move \\
\hline Duerksen and & Suturing & Neutral & & & & PIPJ and DIPJ \\
\hline Schwarz $^{17}$ & Immobilization & Neutral & & & & free to move \\
\hline Palande $^{7}$ & Immobilization & Neutral & $70^{\circ}$ & $70^{\circ}$ & $70^{\circ}$ & free to move \\
\hline \multirow[t]{2}{*}{ Malaviya et ${ }^{16}$} & Suturing & Neutral & All $65^{\circ}$ & & & PIPJ and DIPJ \\
\hline & Immobilization & Neutral & All $65^{\circ}$ & & & free to move \\
\hline Zancolli15 & Suturing & Neutral & Neutral & & & PIPJ and DIPJ \\
\hline Mobile Claw & Immobilization & Neutral & $20^{\circ}$ & & & free to move \\
\hline Claw With & Suturing & Neutral & $20^{\circ}$ & & & PIPJ and DIPJ \\
\hline
\end{tabular}

I M R L = Index, Middle, Ring, Little fingers

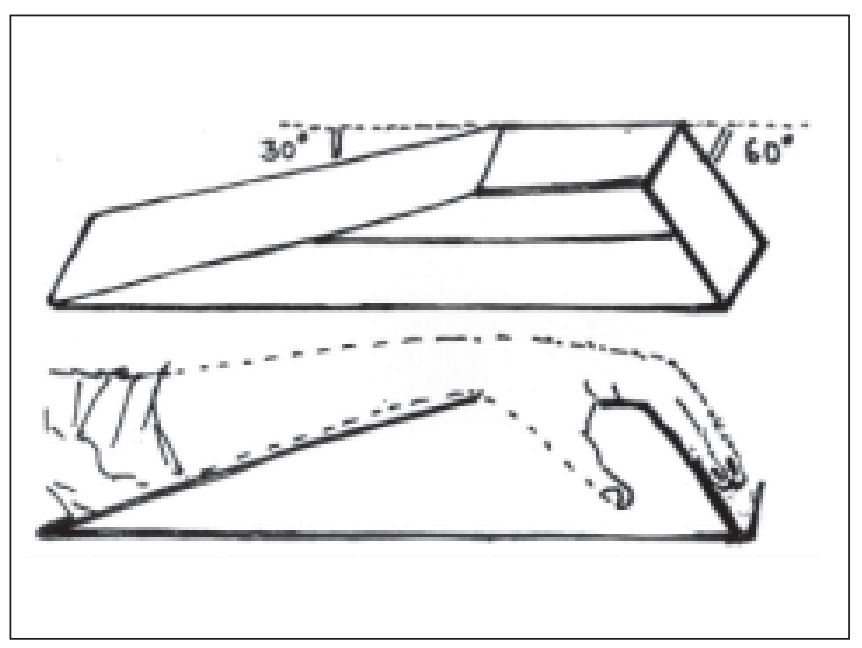

Figure 1: Positioning splint used by Fritschi

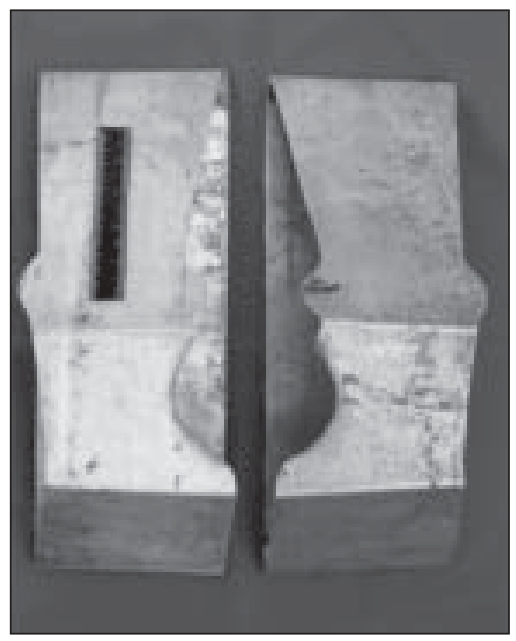

Figure 2A: Positioning splint used by Fritschi to accommodate for DTMA Separate splints for right and left hand, made of aluminium sheet. Splint carved in wood

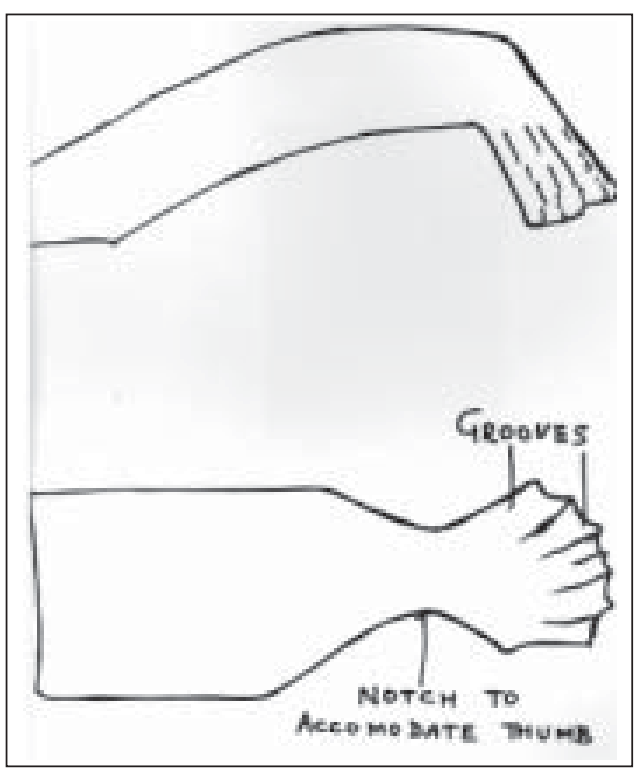

Figure 2B: Splint carved in wood

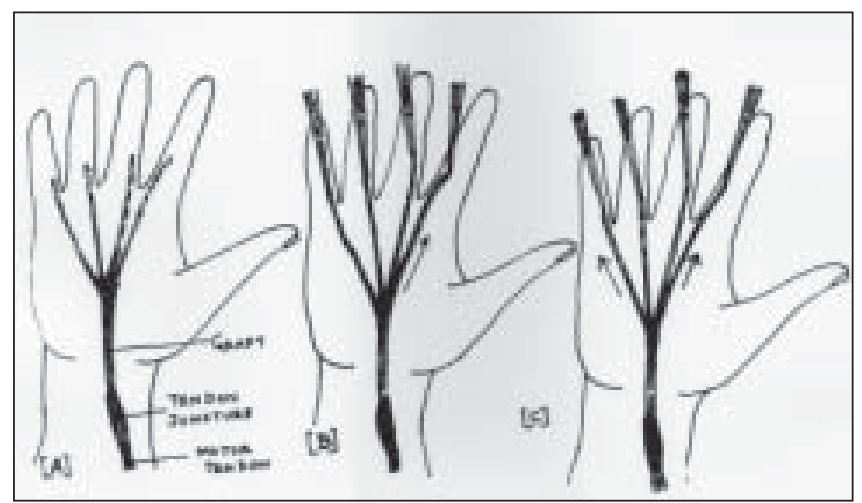

Figure 3: Karat's method to adjust tension A. Tendon slips after tunneling into digits. B. Index finger slip has been pulled. C. Little finger slip pulled to adjust the tension. 


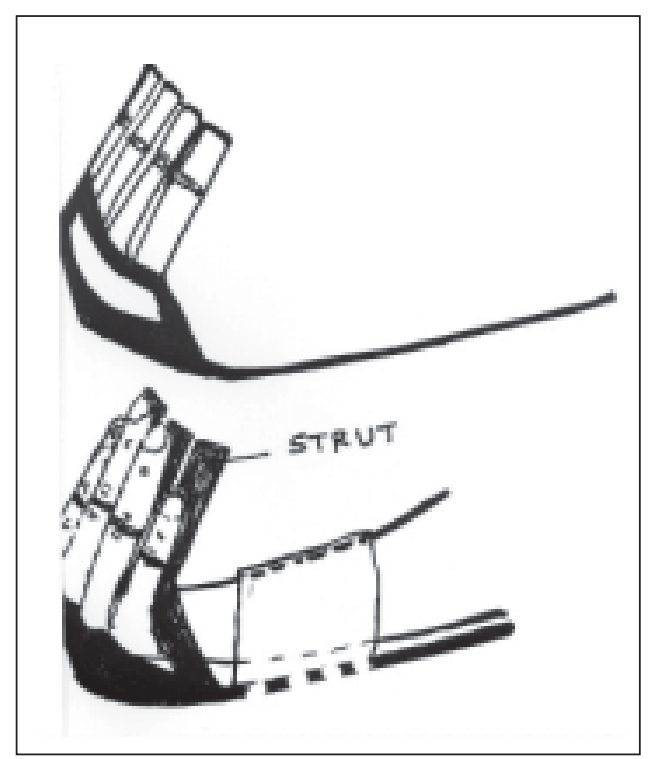

Figure 4: Positioning splint used by Salafia

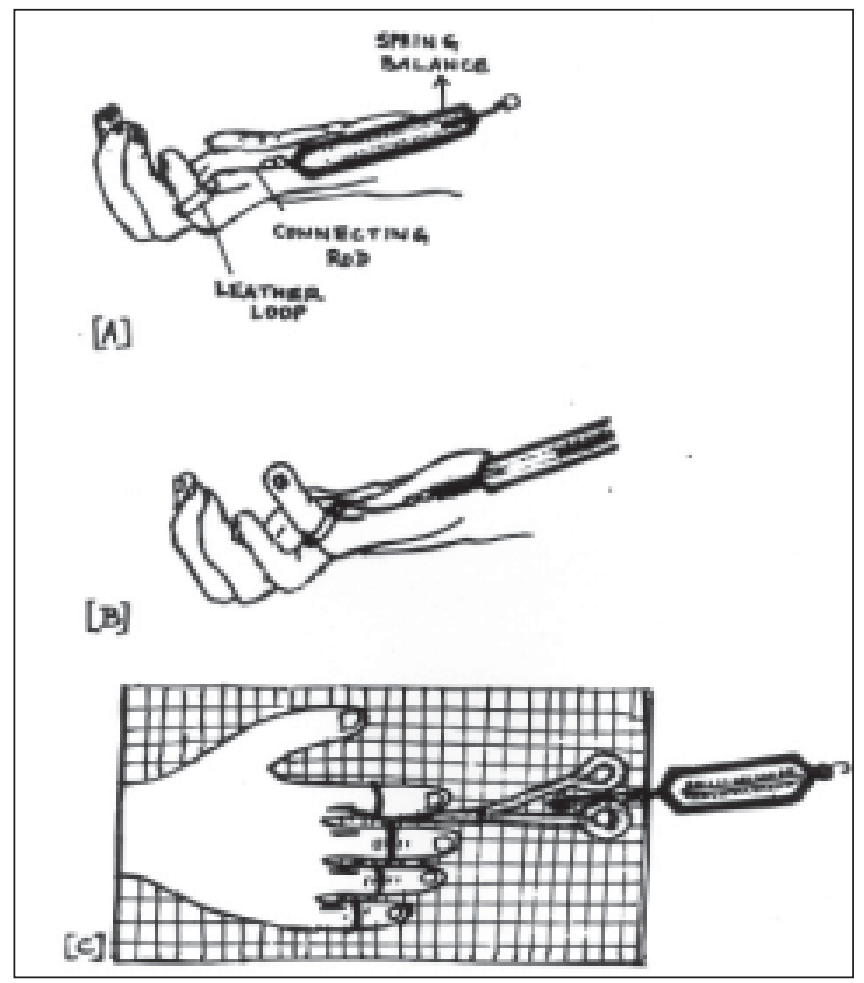

Figure 5: Measured tension technique (adapted from pictures provided by PV Joshi). A. Leather loop in place on little finger B. Leather looped pulled with a spring balance $\mathrm{C}$. Tension adjustment during operation

is important for proper grip function.

The temptation to put extra tension on the finger which is slightly contracted is not desirable. The result of extra tension on one finger results in laxity of other fingers and higher tension finger will tend to precede other three in the process of grasp. The lower tension finger will fail to act along with the higher tension fingers and it may not be

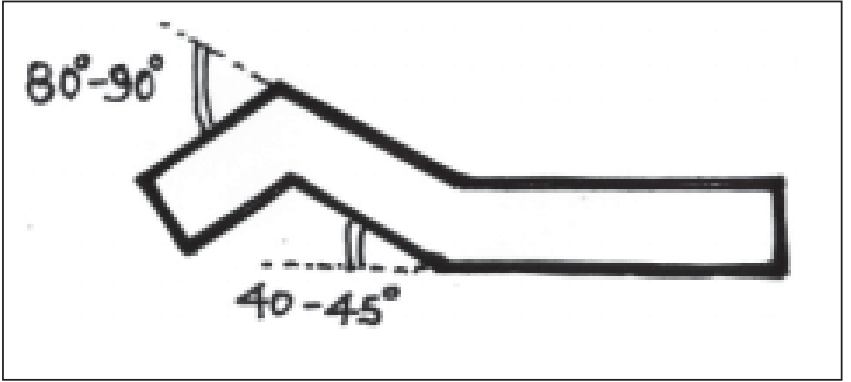

Figure 6A: Brand's splint

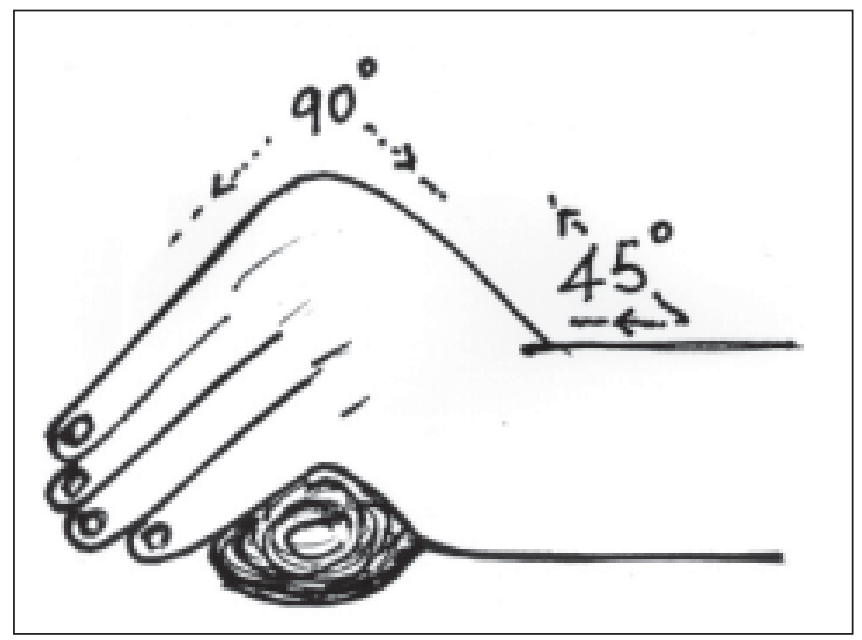

Figure 6B: Brand's method of using rolled towel or gauze roll

possible for an object to be grasped firmly with all four fingers in unison.

Duerksen and Schwarz ${ }^{17}$ have also emphasized the importance of tension in dynamic transfers and suggested to use a splint for positioning the hand. They recommended that wrist should be $30^{\circ}$ flexed, MCP joint $80-90^{\circ}$ flexed and IP joints be in neutral position while suturing. In case the splint was not available, they suggested to use rolled green towels under the palm or a sterilized beer can. In mobile hands no tension is required. Index finger is sutured first and then the little finger which receives $1 \mathrm{~cm}$. more tension than the index so as to restore DTMA. For stiff hands, more than half of total excursion of the transferred tendon be used as tension. e.g. $>10 \mathrm{~mm}$ tension be used with extensor carpi radialis longus having $20 \mathrm{~mm}$ excursion. For postoperative immobilization they keep wrist in slight flexion, MCP joints in full flexion and IP joints in neutral position. Taylor et $\mathrm{al}^{18}$ have used a similar technique as suggested by Fritschi ${ }^{3}$ and were satisfied with the outcome.

Joshi ${ }^{8}$ has shown that amount of tension required to correct deformity of individual finger is not related to the degree of clawing and this probably explains why subjective assessments of tensions pre-operatively failed to produce 
desired results. Measured tension technique has been used by Thatte et al ${ }^{19}$ and Sane et $\mathrm{al}^{20}$ while operating to correct finger clawing. They appear to be quite satisfied with the outcomes. Sane et $\mathrm{al}^{20}$ suggest that if flexor digitorum superficialis (FDS) is transferred, slip to the donor finger is to be given less tension than others (about $50 \mathrm{gms}$. less for normal hands and 100 gms. less for hands with hyper mobile finger joints) because pre-operative measurements are taken when FDS is attached to the donor finger. Measured tension technique appears more rational and will be helpful to the beginners in the field. It can be recommended to be used whenever in doubt. The results are best in patients with fully mobile finger joints since existing finger contractures, if not corrected preoperatively; interfere with the measurements (PV Joshi personal communication). Being little cumbersome, it has not become popular among surgeons.

While several methods of tension adjustment have been described, no method can probably compensate for altered visco-elastic properties of donor muscle-tendon unit under anesthesia. Donor muscles have an ability to compensate for moderate changes in its length- tension relationships ${ }^{14}$. In one study it was suggested that passive tension to guide intra-operative tension may result in overstretching of the muscle-tendon unit which may lead to lower active force generation. ${ }^{21}$

For "lasso" procedures, the slip for the little finger are intentionally tightened in excess of what is required for ring finger because failure to correct claw deformity was seen to occur most of the time in the little finger. ${ }^{14}$

We prefer to make the hand supple, joints fully mobile and correct extensor tendon problems before operating on the claw fingers. For lateral band procedures, we follow the technique as described by Fritschi ${ }^{3}$ and Karat. ${ }^{5}$ Separate splints are used for left and right hands and we immobilize MCP joint in $90^{\circ}$ flexion, wrist and IP joints neutral. However for $10-15^{0}$ extensor lag, to re-enforce the central band, transferred slip is also sutured to it. If residual contracture remains in some finger, FDS from the same finger is used for transfer (except little finger). Excess tension on the lateral bands may interfere with the long flexor action and complete fist closure may not be possible, more so if flexor digitorum profundus (FDP) is weak (in ring and little fingers). ${ }^{22}$ For $10-15^{0}$ residual PIP joint contracture $20 \%$ (1$2 \mathrm{~mm}$ ) extra tension is some times given to the slip going to the contracted finger but results are unpredictable. To be honest, cosmetic outcomes are compromised if residual PIP joint contracture is there and we do inform the patient what to expect in context of appearance of the hand. For lasso procedures, technique described by Malaviya et a ${ }^{16}$ is being used.

In spite of all these explanations, experience does walk in silently and its impact cannot be entirely ruled out. Even though my first case of claw finger correction had residual contractures in the little finger, my suggestion to the beginners is to start their crusade by operating on a fully mobile supple hand and gradually enter deep into the problems as their "experience" builds up. Efforts are being made to work out a reliable method of predicting the functional effect of tendon transfer by measuring intraoperative sarcomere length combined with the data obtained by bio-mechanical modeling using normative values of muscle architecture, tendon compliance and joint movement. ${ }^{23}$ This may help solve the problem of tension balancing in future but "innate capacity" of muscle-tendon unit to respond to stretching seems difficult to be standardized.

\section{REFERENCES}

1. Antia NH, Enna CD, Daver BM. editors. The Surgical Management of Deformities in Leprosy and Other Peripheral Neuropathies. Bombay: Oxford University Press; 1992;70-86.

2. Antia NH. The palmaris longus motor for lumbrical replacement. The Hand 1969;1:139-45.

3. Fritschi EP. Reconstructive Surgery in Leprosy Bristol: John Wright \& Sons LTD; 1971;53-5.

4. Fritschi EP. A new operation hand splint for intrinsic replacement tendon transfers. Lepr. Rev. 1979;50:21-4.

5. Karat S, Furness MA. Reconstructive surgery and rehabilitation in leprosy. Physiotherapy 1968;54:317.(Quoted by Fritschi,1971)

6. Salafia A. Tension equalizer for claw hand correction. Ind. J Lepr 1992;64:209-10.

7. Srinivasan $\mathrm{H}, \mathrm{Palande}$ DD. Essential Surgery in leprosy Techniques for District Hospitals. WHO Publication 1997;96-102.

8. Joshi PV 1992 (Quoted by Antia NH, Enna CD and Daver BM. editors. The Surgical Management of Deformities in Leprosy and Other Peripheral Neuropathies. Bombay: Oxford University Press 1992;85-6).

9. Brand P. Paralytic claw hand: with special reference to paralysis in leprosy and treatment by the sublimis transfer of Stiles and Bunnel. J. Bone Jt Surg. 1958;40-B:618-32.

10. Brand P. Deformity in Leprosy. In: Leprosy in Theory and Practice editors, RG Cochrane and TF Davey. Bristol: John Wright \& Sons LTD; 1964;485-9.

11. Brand P. Surgical treatment of primary deformities of the hand. In: Surgical Rehabilitation in Leprosy. editors. F McDowell and C Enna. Baltimore: The Williams \& Wilkins Company; 1975;225-6.

12. Brand P. Paralysis of the intrinsic muscles of the hand. In: Operative Surgery editors. C Rob and R Smith (Vol. The Hand. editor RG

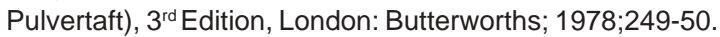


13. Malaviya GN, Srinivasan H. Paralytic claw fingers and its management. In: Textbook of Orthopedics and Trauma. Editor GS Kulkarni. New Delhi: Jaypee Brothers; 1999;674-6.

14. Anderson GA. Ulnar nerve palsy. In: DP Green, WC Pederson, RN Hotchkiss, SW Wolfe, Editors. Green's Operative Hand Surgery. $5^{\text {th }}$ edn. Philadelphia: Elsevier; 2005;1172-9.

15. Zancolli EA: Intrinsic paralysis of the ulnar nerve - physiopathology of the claw hand. In: Structural and Dynamic Bases of Hand Surgery. $2^{\text {nd }}$ edition. Philadelphia: JB Lippincott; 1979;180-1.

16. Malaviya GN, Husain S, Shantagunam P. Correction of hyper mobile claw fingers by pulley insertion procedure. Eur J Plast Surg 1987;10:148-51.

17. Duerksen, Schwarz R. Ulnar nerve palsy. In: Surgical Reconstruction and Rehabilitation in Leprosy and Other Peripheral Neuropathies. editors R Schwarz and W Brandsma. Kathmandu: Ekta Books; 2004;53-4.

18. Taylor NL, Dorai Raj A, Harold MD and Solomon S. The correction of ulnar claw fingers: a follow-up study comparing the extensor-to -flexor with the palmaris longus 4-tailed tendon transfer in patients with leprosy. J Hand Surg 2004;29-A:595-604.

19. Thatte MR, Verma CV, Shah PP, Thatte RL: Measured tension method for surgery of the claw hand. Hand Surg. (Asia Pacific) 1996;1:147-51.

20. Sane SB, Mehta JM, Kulkarni VN. Application of measured tension technique in correction of claw fingers by tendon transfer in leprosy. Ind. J Lepr. 1997;69:63-70.

21. Friden J, LieberRL, Friden J. Intraoperative evidence for muscle attachment at relatively long lengths in tendon transfer surgery. $J$ Hand Surg. 1998;23-A:105-10.

22. Malaviya GN. Unfavorable results after surgical correction of claw fingers in leprosy. Ind. J Lepr 1997;69:71-6.

23. LieberRL, Friden J. Intraoperative measurement and biomechanical modeling of the flexor carpi ulnaris to extensor carpi radialis longus tendon transfer. J Biomech. Eng. 1997;119:386-91. 